\title{
HEALTH SEEKING BEHAVIOUR AMONG ADULT ORANG ASLI (INDIGENOUS PEOPLES) FROM RURAL NEGERI SEMBILAN, MALAYSIA: A MIXED-METHODS STUDY
}

\author{
Muslimah Ithnin ${ }^{1}$, Nadeeya'Ayn Umaisara Mohamad Nor ${ }^{2}$, Norsham Juliana ${ }^{3}$, Nadia Mohd Effendy and \\ Mohd Dzulkhairi Mohd Rani ${ }^{2 *}$ \\ ${ }^{1}$ Faculty of Medicine and Health Sciences, Universiti Sains Islam Malaysia, Nilai, Malaysia \\ ${ }^{2}$ Department of Primary Care, Faculty of Medicine and Health Sciences, Universiti Sains Islam Malaysia, \\ Nilai, Malaysia \\ ${ }^{3}$ Department of Medical Science I, Faculty of Medicine and Health Sciences, Universiti Sains Islam Malaysia, \\ Nilai, Malaysia \\ ${ }^{4}$ Department of Medical Science II, Faculty of Medicine and Health Sciences, Universiti Sains Islam Malaysia, \\ Nilai, Malaysia
}

Corresponding author: Mohd Dzulkhairi Mohd Rani

Email: drdzulkhairi@usim.edu.my

\begin{abstract}
Globally, the minority indigenous peoples have a lower health status when compared with national populations. The Orang Asli who are indigenous peoples of Peninsular Malaysia, also pose a significant challenge towards the handling of diseases. The present study sought to synthesise a coherent explanation of health-seeking behaviour among Orang Asli using a mixed-method research approach. A cross-sectional survey was conducted among 324 adult Orang Asli living in the rural district of Jelebu, in the Peninsular Malaysian state of Negeri Sembilan who conformed to the inclusion criteria. Then, 16 participants were interviewed to obtain an in-depth insight regarding their health-seeking behaviour. The findings showed that the majority of the Orang Asli utilized modern healthcare facilities and the respondents reported that the accessibility, services and medicines provided by the government were excellent. Meanwhile, $40.7 \%$ of the respondents relied on both traditional and modern treatments. The key determinants of the modern healthseeking behaviours among the Orang Asli in this study were satisfaction on modern health, barriers in getting health services, acceptance and attitude, and traditional medicine utilisation. Government, institutions and healthcare facilities have a role in ensuring that the vulnerable Orang Asli population is not left behind in receiving essential information on diseases associated with chronic and infectious diseases, including the current COVID-19 pandemic, as their action of seeking treatment remains complex and multi-layered.
\end{abstract}

Keywords: Health-seeking behaviour, indigenous, survey, in-depth, peninsular Malaysia

\section{INTRODUCTION}

The well-being of indigenous populations ranges in terms of stages, patterns and developments. In most countries, a large gap can be seen between indigenous peoples and non-indigenous population with aspect to socioeconomic status, education and health status ${ }^{1}$. Compared to the nonindigenous population, the health of the indigenous peoples is lagging and health disparities are still apparent ${ }^{1}$. Moreover, indigenous peoples who are undergoing epidemiological and socioeconomic transition are also facing infectious diseases and noncommunicable diseases, including obesity, cardiovascular diseases and diabetes ${ }^{2-4}$. Regardless of their geographical location or sociopolitical situation, health indicators are always lower for the indigenous populations than for nonindigenous populations ${ }^{1}$.

Malaysia is a multi-ethnic country where approximately $80 \%$ of the population is comprised of Malay, Chinese and Indian ethnicities ${ }^{5}$. In addition, there are also the Orang Asli who are an indigenous group in Peninsular Malaysia, comprising of only $0.6 \%$ of the country's population ${ }^{6}$. The Orang Asli, which means original people, is a collective term referring to three ethnic groups that are comprised of the Negrito, Senoi and Proto-Malays. They are further officially grouped into 18 different language sub-groups, based on their physical characteristics, cultural practices and linguistics ${ }^{6}$. Out of the total 853 Orang Asli settlements, only of $0.7 \%$ of them are categorised as towns or cities, while $63.2 \%$ are in the fringe of suburbs and $36.1 \%$ are in the interior of the Peninsular Malaysia 6 .

The Malaysian Ministry of Health $(\mathrm{MOH})$ is the primary provider of health care services to the public in Malaysia. The $\mathrm{MOH}$ is responsible for providing preventive, curative and rehabilitative services to support the health status of the entire Malaysian population, including the Orang Asli minorities ${ }^{7}$. Among the facilities provided by the $\mathrm{MOH}$ for the Orang Asli are the Hospital Orang Asli, transit centres, healthcare clinics and treatment centres, Orang Asli Mobile Team and landing zones in the remote areas $^{8}$. From Malaysia National 
Health and Morbidity Survey (NHMS), it is reported that government facilities were the preferred choice amongst Orang Asli and majority of Orang Asli used savings as a mean to pay for healthcare?

Despite the MOH's effort in establishing an extensive network and cost-effective healthcare services in the Malaysian healthcare system, there are still issues in how these services are used by the Orang Asli. The Temuan sub-tribe is one of the Proto-Malay groups of Orang Asli and is found mainly living in fringe settlements in southern and central states of Peninsular Malaysia ${ }^{10}$. These communities have undergone urbanisation, and there have been changes in the use of the health system in these communities.

Among the Temuan community, assimilation with the surrounding community has made them recognise the use of modern health care, which led to many of them seeking medical treatment provided by the government ${ }^{11}$. Nevertheless, similar to many indigenous peoples around the world, there exist a proportion of the community who are still persistently lagging in health-seeking behaviour towards modern healthcare facilities, influenced by barriers and traditional medicines used ${ }^{12,13}$. This situation is worrying as according to previous studies, there is an emergence of noncommunicable diseases (NCDs) together with infectious diseases in these vulnerable communities $^{14,15}$. The increasing prevalence of NCDs is a significant concern, as these diseases require long-term care and treatments which can increase the burden of the conditions in these vulnerable communities ${ }^{16}$.

Health-seeking behaviour is the quantity, quality, management, traits and relationships with resources in the process of getting treatment or medicine ${ }^{17}$. According to MacKian, ${ }^{18}$ in understanding health-seeking behaviours, research into this topic is commonly conducted in two-components. The first component is to conduct studies on the causal factors in the use of health services, also known as utilisation of the formal system, or healthcare-seeking behaviour. The second component is to study the determining factors that cause people to behave differently concerning their health, which emphasise the illness response, or health-seeking action.

The present research is a mixed-methods study with quantitative and qualitative elements to answer the research aims to provide strong inference and complement the strength of each methodology in providing more meaningful, indepth data ${ }^{19}$. Thus, a cross-sectional survey was conducted to determine the health-seeking behaviour, and accessibility of the government healthcare facilities and also accessibility of medicines and treatments from government healthcare facilities. Then it was followed by indepth interviews that aimed to understand the practices and barriers concerning the healthseeking behaviour among the Orang Asli.

\section{METHODS}

The present study included formative research of explanatory sequential mixed-methods interviews. A quantitative survey followed by an explanatory qualitative in-depth interview was the chosen sequence of mixed-methods. ${ }^{19}$ The data for this research were obtained from both quantitative and qualitative phases, collected and analysed separately then combined to better understand the utilisation and perspectives of health care seeking behaviour by the Orang Asli.

\section{Study area}

The research took place in the rural district of Jelebu, in the Peninsular Malaysian state of Negeri Sembilan. The Temuan sub-tribe belongs to the Proto-Malay group of Orang Asli and is the main Orang Asli tribe living in Jelebu, comprising an estimated $7.5 \%$ of the total population in Jelebu ${ }^{5}$. The Orang Asli villages are categorised as fringe settlements. They have good accessibility to amenities such as piped water, electricity supply and connecting roads to their surrounding communities.

Additionally, there is also a land development project and a sustainable economic source for them. Nevertheless, their economic status is still below the poverty line as many have unstable incomes. Even though some of the Orang Asli carry out rubber tapping activities and oil palm cultivation, they also still depend on the traditional economic activity of selling forest goods $^{6,11,12}$.

In terms of healthcare facilities, there is a nearby government hospital called Hospital Jelebu, located at the town of Kuala Klawang. It is a nonspecialist district hospital with 76 beds. The hospital provides outpatient and inpatient services. In addition, the government also provides a mobile clinic with doctors and nurses under the Jelebu District Health Office. The mobile clinics visit the Orang Asli villages twice every month.

\section{Study population and sample}

The study population included adults of Orang Asli ethnicity aged 18 and above. All of the participants understand and can speak the Malay language very well, which facilitated the data collection process. After the meeting with the community leader of Orang Asli in Jelebu, eleven villages with a total of 681 households agreed to participate in the study.

For the quantitative survey, the sample size determined is as follows $n=z^{2} \times p \times(1-p) / e^{2} .{ }^{20}$ With a population size $(n)$ of 2532 , at confidence level (z) of $95 \%$, margin of error (e) of $5 \%$, population 
proportion $(p)$ of $50 \%$, the total number of respondents required was calculated to be 334 . The selection of respondents for the structured interviews was performed using the convenient and snow-balling sampling method based on the defined inclusion and exclusion criteria due to the shy behaviour and limited number of Orang Asli available during the time of the interviews, it was often hard to reach the people to be selected. Both purposive and snowball sampling approaches are non-random sampling methods which may have limitations but are normally used in Orang Asli research ${ }^{21,22}$.

A village was purposely selected as the study site for the follow-up qualitative interview. This village enabled the investigators to understand the critical issues related to proximity to health services and the use of modern health care services. This village is located near the Jelebu town, with good premix roads connecting the communities to other villages and towns. Located $9 \mathrm{~km}$ from Jelebu town, the nearest government clinic and the hospital is Klinik Desa Ulu Klawang and Hospital Jelebu that are located $1.7 \mathrm{~km}$ and $11.0 \mathrm{~km}$, respectively from the village. As the village has good accessibility to modern facilities, it was assumed that the Orang Asli village had no barriers in getting modern health treatments.

The inclusion criteria were individuals aged between 18 years old and above who provided informed consent. They shall be the ethnicity of Temuan Orang Asli. Anyone with mental or physical disabilities or those who pregnant excluded. Individuals who did not understand the Malay language also excluded since the survey was conducted in Malay.

\section{Instruments and data collection}

A mixed-methods sequential explanatory questionnaire was administered. The interview guide and questions were validated by experts from Universiti Sains Islam Malaysia and community members from the study communities before formal data collection began. A pre-test with thirty respondents who had a similar profile to the target population conducted to verify the reliability of the questionnaire. Cronbach's a coefficients used to evaluate the reliability of the accessibility items. The Cronbach's a coefficient is 0.833 .

The quantitative survey was conducted from January 2018 to February 2019. In the survey, a series of 27 closed-ended questions regarding demographics, questions asked to the respondents on their actions in seeking treatment and their reasons for not seeking treatment if they did not do so. Additionally, information about any traditional medicine used to heal any illness was also gathered.

Then, the respondents were asked about accessibility in two sub-sections. Four items asked on the accessibility to government healthcare facilities including:

(a) distance, transportation, (c) operational hours and (d) waiting times for treatment. In addition, another five items queried on accessibility to medicine and treatments from government healthcare facilities. This was to understand the utilisation, demand for service, perceptions of quality of care and health belief among the Orang Asli ${ }^{20}$. The answer options both sections were 'Yes', 'No' and 'Unsure'. The The quantitative survey lasted between 15 and 20 minutes.

Then, follow-up, in-depth interviews were conducted using semi-structured interviews that consisted of several key questions that helped to define the areas explored, but also allowed the interviewer or interviewee to diverge and pursue an idea or response in more detail ${ }^{19}$. The questions contextualised respondents' responses to the quantitative questions, providing them the opportunity to: (1) explain their health-seeking decisions, (2) express their opinion regarding the health services and (3) health-seeking behaviour of other Orang Asli in the community.

The semi-structured interviews were determined based on saturation and the investigators ceased recruitment when the information reported by respondents became redundant and no new themes were emerging ${ }^{23}$. The interview respondents were recruited in April 2019. Appointments were scheduled and agreements regarding the time and the venue for the interviews were made. Purposive sampling was performed in which the best respondents that could address the research question were chosen ${ }^{23,24}$. During the quantitative phase, respondents were informed about the possibility of a second data collection which was the qualitative process. To ensure the maximum variation of respondents, they were selected based on different genders, education, household income range from low to high incomes, and health status.

The saturation point was monitored continuously throughout the recruitment. After the 14th interview, there was no new theme emerging from the interviews. Therefore, it was considered that the data collection had reached a saturation point. However, data collection was continued for two more interviews to confirm that there were no further new themes.

As proof of the qualitative research's reliability, the conversations were recorded using an audio recorder during the interviews. Audio recording enables the interviewer to preserve the actual language of the interviewee, thus increasing the accuracy of the data collection. The qualitative in-depth interviews lasted between 20 and 30 minutes.

\section{Data analysis}

The survey data was organised, cleaned, and analysed using the Statistical Package for the Social Sciences (SPSS) Version 23 statistical 
software. The quantitative data was analysed to obtain descriptive statistics, including frequencies, means and ranges of responses.

For the qualitative data analysis, the process followed the procedures set by Creswell and Hirose $^{25}$. After an was interview carried out, the audio recording was transcribed and organised for data analysis. As stated by Rowley ${ }^{24}$, the process of transcribing should be done as soon as possible after each interview to making sense of the interview data. To aid in transferring and coding, the interview conversations were typed into Microsoft Word after the interview sessions. Qualitative data processing was organised in three rounds. In the first round, a codebook was created based on interview questions and answer codes were inductively developed based on the first 10 participants' answers.

In the second round, the first 10 transcripts were duplicated to ensure a coders' consensus, to address any inconsistencies in codes and to extend or modify the meanings of codebooks as required. Finally, the codebook was added to the remaining transcripts, and the research team met to review the quotations for each code, to synthesise the content and to compare inside and through the transcripts, essential quotations that best represented each theme. The translation of the chosen quotes was checked by a second translator to ensure accuracy. The data were then presented in the form of a narrative and quotation obtained from an interview transcription. The quantitative and qualitative results were both presented to triangulate and confirm the responses provided. By triangulating the responses, we can understand the Orang Asli health-seeking experiences, opinions and utilisation regarding the health services.

\section{Ethical clearance}

This study was submitted to the Universiti Sains Islam Malaysia Ethics Committee, Malaysia Research Ethic Committee, Ministry of Health of Malaysia $(\mathrm{MOH})$ via the National Medical Research Registration (NMRR) and authorities of the Department of Orang Asli Development (JAKOA), Malaysia. The ethical clearance and permission to conduct this study were obtained from the USIM Ethics Committee, Malaysia Research Ethic Committee and JAKOA, respectively. The NMRR research identification number was NMRR-183111-44674(IIR), and the USIM Ethics Committee identification number was USIM/REC/FPSK-081735. The approval letter from JAKOA was JAKOA/PP.30.052 Jld14(24).

\section{RESULTS}

Quantitative results

The quantitative results are divided into four sections: demographic information, health seeking behaviour when ill, accessibility to health facility and accessibility to medicine and treatment.

\section{Demographic characteristics}

A total of 324 participants were involved in the survey. The demographic survey results are summarised in Table 1. The mean age of the respondents was 39.99 years old, with a standard deviation of 13.186, and the range being 18-83 years old. The mean income was Ringgit Malaysia (RM) 616.81 (150.72 United States Dollar), with a standard deviation of RM446.82

\section{Health-seeking behavior}

From the 324 participants who sought treatment, $59.3 \%$, sought modern treatments while another $40.7 \%$ relied on both traditional and modern treatments. For modern treatments, the majority of respondents preferred the government clinic followed by the government hospital, private clinics and pharmacies (retail drugstore) with a percentage of $96.0 \%, 3.1 \%, 0.6 \%$ and $0.3 \%$, respectively. Whereas, for traditional medicine, $55.1 \%$ used ointments and $39.0 \%$ used medicines and treatments given by their traditional healers. Another $5.9 \%$ used the natural resources of roots and shoots from the forest nearby their settlement.

\section{Accessibility to health facility}

The majority of the respondents agreed that the health facilities are close to their homes $(83.3 \%)$, have no transportation issues $(86.5 \%)$ and the operating hours of the facilities are suitable (96.3\%). Despite this, $41.4 \%$ of the respondents felt that the waiting times at the government health care facilities are too burdensome. The responses are summarised in Table 2.

\section{Accessibility to medicine and treatment}

For accessibility to treatment and medicines, the majority of the respondents agreed that the accessibility was good. The respondents stated that the facilities are in good condition $(98.5 \%)$, medications are readily available $(99.4 \%)$, with modern medicines being easier to access compared to traditional medicines (93.8\%). Additional, $93.7 \%$ felt comfortable and will continue to seek treatment at the government health care centre, and $99.1 \%$ will recommend family members and friends for treatment at a government health care centre. The reported response rates are summarized in Table 3. 
Table 1. Demographic characteristics of participants in the survey

\begin{tabular}{|c|c|c|c|}
\hline Demographic characteristics & $\begin{array}{l}\text { Overall, } \\
(n=324)\end{array}$ & Male, $(n=93)$ & $\begin{array}{l}\text { Female } \\
(n=231)\end{array}$ \\
\hline \multicolumn{4}{|l|}{ Marital status } \\
\hline Never married & $28(8.6)$ & $13(14.0)$ & $15(6.5)$ \\
\hline Currently married & $274(84.6)$ & 78 (83.9) & $196(84.8)$ \\
\hline Separated/divorced & $14(4.3)$ & $1(1.1)$ & $13(5.6)$ \\
\hline Widow/widower & $8(2.5)$ & $1(1.1)$ & $7(3.0)$ \\
\hline \multicolumn{4}{|l|}{ Education } \\
\hline No formal education & $104(32.0)$ & $31(33.3)$ & $73(31.6)$ \\
\hline Attended primary school but did not finish & $79(24.4)$ & $24(25.8)$ & $55(23.8)$ \\
\hline Primary school & 47 (14.5) & $10(10.8)$ & $37(16.0)$ \\
\hline Attended secondary school but did not finish & $38(11.7)$ & $10(10.8)$ & $28(12.1)$ \\
\hline Secondary school & $43(13.3)$ & $14(15.1)$ & $29(12.6)$ \\
\hline Tertiary education & $13(4.0)$ & $4(4.3)$ & $9(3.9)$ \\
\hline \multicolumn{4}{|l|}{ Occupation } \\
\hline Employed & $184(56.8)$ & $84(90.3)$ & $100(43.3)$ \\
\hline Unemployed & $140(43.2)$ & $9(9.7)$ & $131(56.7)$ \\
\hline \multicolumn{4}{|l|}{ Employment category } \\
\hline Government & $8(4.3)$ & $2(2.4)$ & $6(6.0)$ \\
\hline Private & $3(1.6)$ & $1(1.2)$ & $2(2.0)$ \\
\hline Self-employed & $173(94.0)$ & $81(96.4)$ & $92(92.0)$ \\
\hline \multicolumn{4}{|l|}{ Unemployment category } \\
\hline Home maker & $127(90.7)$ & $3(33.3)$ & $124(94.7)$ \\
\hline Unemployed & $10(7.1)$ & $5(55.6)$ & $5(3.8)$ \\
\hline Students & $3(2.1)$ & $1(11.1)$ & $2(1.5)$ \\
\hline
\end{tabular}

Table 2: Reported characteristics of health facility accessibility $(n=324)$

\begin{tabular}{lc}
\hline Characteristic & $n, \%$ \\
\hline The distance between home and the government health care centre is close & $270(83.3)$ \\
Experience no transportation problems to get to government health care centre & $281(86.5)$ \\
Operating hours for government health care centres are suitable & $312(96.3)$ \\
Waiting time at the government health care centre is not burdensome & $190(58.6)$ \\
\hline
\end{tabular}

Table 3: Reported characteristics of health services and medicine $(n=324)$

\begin{tabular}{ll}
\hline Characteristic & $n, \%$ \\
\hline Government health care facilities in your area are in good condition & $319(98.5)$ \\
Medicines can be obtained from government health facilities (hospitals/clinics) & $322(99.4)$ \\
Modern medicine is more readily available than traditional medicine & $304(93.8)$ \\
Feel comfortable and will continue to seek treatment at the government health & $323(99.7)$ \\
care centre & $321(99.1)$ \\
Recommend family members and friends for treatment at a government health & \\
care centre & 3
\end{tabular}

\section{Qualitative results}

Sixteen respondents participated in in-depthinterviews, with the mean age being 39 (SD= 13.88 ) years old and mean income RM606.25 (SD= 343.45) equivalent to USD 148.14. Five of the respondents were males, and for education background, $25.0 \%$ had no formal education while another $25.0 \%$ only completed secondary school. The qualitative portion of the interviews aimed to contextualise the quantitative responses summarised above. It included questions on satisfaction and perspectives on health services provided. Across the health care services mentioned, key themes emerged from the data as the main individual-and contextual-level influences on the health-seeking behaviours of Orang Asli in this community which were: (i) satisfaction to modern health, (ii) barrier in getting health services (iii) poor attitudes and (iv) traditional medicine utilisation. These themes did not appear to differ between the study community. The illustrative quotes for each theme are presented in Table 4. 
Table 4: Illustrative quotations

\begin{tabular}{|c|c|}
\hline Theme & Quotations \\
\hline $\begin{array}{l}\text { Satisfaction to modern } \\
\text { health }\end{array}$ & $\begin{array}{l}\text { The clinic facilities were excellent. If any of our children is sick, we will } \\
\text { bring them to the clinic. (L, } 35 \text { years old) } \\
\text { Healthcare facilities here are the best. If I need to go to the clinic, my kids } \\
\text { will send me there with their motorcycles. My health condition is satisfying. } \\
\text { I do not have hypertension or diabetes. I am used getting a check-up, I am } \\
\text { not afraid. If we get sick, we need to see a doctor for treatment and take } \\
\text { the medicine. (R, } 50 \text { years old) } \\
\text { I took modern treatment when I was sick. Previously I had a cough with } \\
\text { blood. I went to the hospital and I took the medicine given by the doctor. } \\
\text { After seeing the doctor, I became healthier. I no longer have those problems. } \\
\text { (D, } 47 \text { years old) } \\
\text { I am no longer take any traditional medicines. I also did not take tree roots } \\
\text { from the woods. If I sick, I will go to the hospital. ( } \mathrm{N}, 33 \text { years old) }\end{array}$ \\
\hline $\begin{array}{l}\text { Barrier in getting health } \\
\text { services }\end{array}$ & $\begin{array}{l}\text { Since I had hypertension, it's hard to do farming. There is a pain in the leg, } \\
\text { leg pain. Haven't seen a doctor for over a year. It's hard as I don't have } \\
\text { transportation. My husband didn't send. (L, } 51 \text { years old) } \\
\text { I need to wait for my husband or kids to send me. I know how to ride a } \\
\text { motorcycle but I do not have a license. (R, } 44 \text { years old) }\end{array}$ \\
\hline $\begin{array}{l}\text { Acceptances and } \\
\text { attitude }\end{array}$ & $\begin{array}{l}\text { When my husband was sick, I asked him to go to the hospital he refused. We } \\
\text { cannot even mention about the hospital to him as he was afraid to go to the } \\
\text { hospital. ( } \mathrm{S}, 52 \text { years old) } \\
\text { As for the villagers, they will take the modern cures for illnesses such as for } \\
\text { the common fever, using painkiller medicines. Meanwhile, if for diabetes, } \\
\text { high blood pressure, then they will take the roots from the woods. (J, } 53 \\
\text { years old) } \\
\text { For those with diabetes and hypertension, they need to take their medicine } \\
\text { at Klinik Desa (Rural Clinic) near this village. Even though it is just nearby } \\
\text { the village, it is hard for them to go. Sometimes these people just forget. } \\
\text { (F, } 35 \text { years old) }\end{array}$ \\
\hline $\begin{array}{l}\text { Traditional medicine } \\
\text { utilisation }\end{array}$ & $\begin{array}{l}\text { The traditional medicines were not easy for us to practice. Previously, my } \\
\text { late grandparents have taught me. However, when he died, the practices I } \\
\text { could not continue as I do not understand how to do it. I also had no skills. } \\
\text { The natural resources like the roots are still available in the forest. However, } \\
\text { for me, I do not understand. To find it in the woods also quite far away. We } \\
\text { need to have the knowledge to look for it. (R, } 50 \text { years old) } \\
\text { I did teach my kids about these traditional food and medicines. But my kids } \\
\text { do not want. So, I take it for myself. ( } S, 52 \text { years old) } \\
\text { For those having diabetes, high blood pressure, they usually eat their } \\
\text { traditional medication. They will find the medicinal plant roots from the } \\
\text { nearby forest. They find it themselves. ( } F, 35 \text { years old) }\end{array}$ \\
\hline
\end{tabular}

\section{Satisfaction to modern health}

All the respondents had experience of using modern medical treatments for the treatment of illnesses. For many of the respondents, the accessibility to government healthcare was good. Since many are relying on modern medicine, the respondents noted the importance of having access to a healthcare facility. Supporting the quantitative survey finding, the interview respondents stated that they rely on modern medical treatments for health care. As stated by the respondents, since the government had provided the healthcare facility near their settlement, they will still use it even if there was no public transportation by relying on their family members. In addition, based on their experience, the use of modern medical treatment was effective in treating their illnesses. Since the Orang Asli are undergoing urbanisation, there is an increasing concern to lifestyle diseases. The respondents also stated that they used government services for health screening.

\section{Barriers in getting health services}

The qualitative interviews identified several barriers regarding the use of modern health care facilities. From Table 2, the majority of the respondents reported having less barriers to access healthcare facilities. Nevertheless, from the in-depth interviews, we found that the 
respondents had to rely on their spouses and firstdegree relatives in seeking modern healthcare treatment, which limited their access to healthcare facilities. As commented by a respondent with hypertension, she was unable to continue her follow-up treatment due to a transportation problem. If their family members were reluctant to send them, then they would have limited access to the facilities.

\section{Acceptances and attitudes}

Individual attitudes influence their behaviour in seeking treatment. Even though the majority of respondents used modern medical treatments, there were some members in the community who still have a fear of using modern medical treatments. When the respondents were asked on the medicines used for treatment and type of illness, they stated that they will use modern medicine for common illnesses such as fevers. However, for the treatment of high blood pressure and high blood glucose, the respondents reported that they used medicinal plant roots from the nearby forest, based on the knowledge they attained from the older generations. Even though the health care facilities are available nearby their settlement, a poor attitude among those with chronic diseases was found, where forgetfulness was the common excuse given for not going to follow-up appointments for diseases monitoring.

\section{Traditional medicines utilisation}

For the traditional medicine used, the respondents described that knowledge of traditional medicine was passed to them through lessons given by the older generation. However, many of the younger generation have limited knowledge of traditional medicine. While some of the elders are still practising traditional medicine, the younger generation seems to be uninterested in using it. Since modern medicine is readily available as summarised in Table 3 , the respondents rely more on modern medication for the treatment of illnesses. However, for individuals with chronic diseases, the reliance on traditional medicine is more common, where they use the natural resources available in the forest nearby their settlement.

\section{DISCUSSION}

The Orang Asli community can no longer be viewed as an isolated community, especially with the Malaysian government's efforts to develop the economy, education and health of the Orang Asli ${ }^{1}$. The Orang Asli community are now more open and accessible to the medical treatments and services provided by the Malaysian government ${ }^{5}$. For the Temuan, they mostly live in the central states of Peninsular Malaysia and are living in urban settlements, such as the Temuans of Bukit Lanjan, Selangor ${ }^{26}$ or in suburban areas, such as the Temuans of Jelebu, Negeri Sembilan ${ }^{11}$. Since these Orang Asli settlements are located near
Malay villages and towns, they had frequent contact with outsiders and modern facilities ${ }^{11}$.

From the survey, we found that the low socioeconomic status remains a major issue of this vulnerable community. Poorer health is related to an individual's socio-economic position, along with low education, illiteracy and poverty ${ }^{27}$. Only $28.9 \%$ of the respondents have attained secondary and tertiary levels of education. From that, only $24.6 \%$ of them completed secondary school, less than half of the national average of $72.0 \%{ }^{28}$. From the observations and field notes during the interview sessions, the investigators found that the respondents had limited ability to read and write. Most of the Orang Asli work in the agricultural field and for those who are working, the majority of them are self-employed with no stable income every month ${ }^{11}$.

Due to the socio-economic vulnerability of this community, and in line with the Malaysian government's objective to improve the health of the Orang Asli community, the government has undertaken various health initiatives for the welfare of this community ${ }^{6}$. In addition to reducing the health care accessibility issues encountered by this community, the Orang Asli are also receiving periodic visits from the district health office ${ }^{29}$. Thus, the majority of the Temuan Orang Asli have accepted modern medical treatments, as almost all of the respondents interviewed have used modern medicine to cure illnesses.

According to the respondents, the quality of services provided by the government was excellent, convenient, near to their housing areas, and the medicine is also readily available and effective in treating their illnesses. Our results are also supported by a previous study done among a Proto-Malay tribe by Rosnon et al. ${ }^{11}$ which reported $92.6 \%$ of their respondents used government clinics or hospital services in the treatments of illnesses. In contrast, studies among Orang Asli living in deep forests and inland locations have reported the opposite situation. The Semai from the Senoi group ${ }^{30}$ and the Batek from the Negrito group ${ }^{31}$ are still primarily practising traditional lifestyles and medicine, especially in the healing of ailments.

Nevertheless, there are also some obstacles faced by the Orang Asli in getting modern treatments. A major obstacle is transportation to the health care facilities for some of the respondents. The findings from our study and a previous study showed that the major form of transportation among the Orang Asli is a motorcycle ${ }^{11}$. Financial factors cause car ownership to be low among the Orang Asli. Therefore, the most frequent transportation utilised by them to go to the neighbouring health care service centre is by motorcycle ${ }^{32}$. However, due to driving licence issues, some of the Orang Asli had to rely on their 
first-degree relatives and spouses instead. This situation is even more burdensome for individuals with chronic diseases which need regular monitoring and check-ups at the health care facilities for the treatment to be effective and to prevent complications ${ }^{33}$. As such, their family members' knowledge may also influence the decision on long-term diseases management among diagnosed individuals, including for regular follow-ups and disease monitoring. Support from the first-degree relatives and spouses is essential in ensuring individuals with chronic diseases can receive the best treatments for diseases management ${ }^{34,35}$. Therefore, studies on health literacy, beliefs and behaviour among the family members of chronic patients are worth exploring to identify associated factors, beliefs and practices that in all probability contribute to the lack of support among chronic diseases patients, particularly in the Orang Asli communities.

The decision to receive modern medical treatments also influences individual attitudes and acceptance of modern medicine. Some of the Orang Asli still have a fear of taking modern medication. The Orang Asli's acceptance of modern health services is more complex and multi-layered than the other major ethnicities in Malaysia as it is profoundly influenced by their traditional health system, their history and ongoing experience process ${ }^{16,36}$. For the indigenous people, it is a common practice to mix the medical systems 16,37 .Traditional medicinal knowledge is passed down through the generations from their elders. Even though some of the respondents knew about these traditional practices, the seems to be a declining trend in its use due to the decreased number of older generations, lack of interest by the younger generations, dwindling numbers of natural resources and lack of traditional knowledge and practices. Therefore, the use of modern treatment is more preferred by them, particularly in treating common fevers or illnesses.

With urbanisation, the Orang Asli in this village underwent a great deal of modernisation. 11,27 They were provided with various facilities and economic sources to elevate their socio-economic status. However, modernisation also affected their health as they became accustomed to unhealthy behavioural risk factors of chronic diseases. ${ }^{14}$ Findings of this study uncovered poor health literacy, knowledge deficit and barriers to seeking medical treatment. The health behaviour of an individual could influence the risk of developing chronic diseases. ${ }^{21}$ Faced with inadequate knowledge of chronic diseases and barriers to a healthy lifestyle, their risks of developing chronic diseases increased. ${ }^{15,37}$ Some of the respondents also claimed that they faced certain barriers in receiving modern treatment. Furthermore, there were some conflicting opinions between traditional and modern medicines as the treatment of the choice for NCDs.

For the Orang Asli, the challenge in chronic diseases treatment and monitoring should be studied in multiple aspects, including the factors of reluctance, hesitation and compliance. This study did not explore further on the local knowledge of the use of natural resources to cure chronic conditions. However, some respondents reported the use of traditional medicines for the treatment of chronic diseases, including hypertension and diabetes mellitus. A previous study revealed the ethnomedicine used by the Temuan tribes of Orang Asli in the sub-urban area of Hulu Langat, Selangor who are utilising natural resources as natural remedies for treating chronic disease as hypertension and diabetes. ${ }^{38}$ Thus, a future extensive research of can be conducted on the traditional medicine used for chronic diseases, the safety and dosage issues.

Moreover, with the current coronavirus disease 2019 (COVID-19) pandemic, the Orang Asli who already experience higher rates of communicable and noncommunicable diseases, are posed with a serious health threat ${ }^{39}$. As the pandemic COVID-19 still ongoing worldwide and in Malaysia, the Orang Asli are becoming even more vulnerable due to low sanitation, socio-economic marginalisation, and poor health literacy, low knowledge on diseases and underlying health conditions ${ }^{40}$. As also reported in the present study, the Orang Asli health-seeking behaviour towards modern medicine and use of traditional knowledge and practices are influenced by multiple factors and barriers. Therefore, understanding how Orang Asli communities engage with health systems can be a useful tool for describing how individuals engage with services ${ }^{1,18}$. By combining quantitative and qualitative research data on health-seeking behaviour, researchers and interested parties could explore the broader relationship between populations and health systems development, as the burden of infectious and chronic diseases is not only at the individual level, but also at the level of communities and the government in general ${ }^{19,25}$.

\section{Limitations}

This study sought to assess health-seeking behaviour among the Orang Asli. The results of our research may not suffice to represent the whole health-seeking behaviour situation of the Orang Asli in Peninsular Malaysia. This is due to the study only being conducted at the specific area of Jelebu, Negeri Sembilan and which only focused on the Temuan sub-tribe which is just one amongst the six subgroups of Proto-Malays. As previously mentioned, there are another two main groups of Orang Asli which are the Negrito and the Senoi, with each group comprising of six subgroups with ethnolinguistic differences that may have different health behaviour risks. 
Secondly, during the interview sessions, all of the information obtained was self reported. Thus, a bias toward socially desirable answers and practices might exist. Some of them appeared less sincere and tended to lie about their answers. This is a general psychological barrier limiting our accuracy in the research. Nevertheless, the quantitative outcomes were also compared and contrasted with the qualitative findings, similar to triangulation design methods, in order to verify or refute meaningful information extracted from the interviews.

Thirdly, in this study, we did not measure the association of the demographic background of respondents with their health-seeking behaviour as this study aim was to explain the finding from the quantitative survey using the in-depth interview. Thus, further study on this can be conducted as health-seeking behaviour can be associated with demographic background particularly for Orang Asli living in the in-deep settlement category.

Finally, the unexpected disproportionally higher number of female respondents in our sampling could also lead to a study bias. This gender imbalance could be due to the males having to work elsewhere on the weekdays and insufficient time allowed for the interviewing process, where the permitted time of the interviews was during the daytime due to security reasons.

\section{CONCLUSION}

Our study found that the majority of the Orang Asli respondents indicated that they utilise most of public healthcare services available to them in their community. They also reported overall satisfaction with the services. However, some respondents reported barriers in utilising the health services which were due to individual acceptances and attitudes, lack of transportation and also the use of traditional medicines, particularly for the treatment of chronic diseases. Policy makers can use the information collected by this study to address the individual- and contextual level factors affecting health-seeking behaviours of the Orang Asli, tackling barriers and increasing utilisation and effectiveness of services. In particular, improving health awareness on the importance of chronic diseases monitoring among the Orang Asli is crucial, as these diseases can progress to short- and longterm disabilities and also premature deaths.

Financial Sponsorship: USIM / BANKRAKYAT_K1 / FPSK / 052002/42117 Grant under the Mizan Research Center, Universiti Sains Islam Malaysia, Malaysia.

\section{Conflict of Interest}

There is no conflict of interest with regard to the study.

\section{Acknowledgement}

The authors are very grateful to the participants who were involved directly and indirectly in this study. The authors would also like to thank the Health Department of Jelebu and The Department of Orang Asli Development (JAKOA), who contributed their time and energy. We would like to acknowledge the Director-General of Health Malaysia for the permission granted to publish this article.

\section{REFERENCES}

1. Anderson I, Robson B, Connolly M, AlYaman F, Bjertness $E$, King $A$, et al. Indigenous and tribal peoples' health (The Lowitja Institute Global Collaboration): a population study. Lancet 2016; 388:131157.

2. Harris SB, Tompkins JW, TeHiwi B. Call to action: a new path for improving diabetes care for Indigenous peoples, a global review. Diabetes Res Clin Pract 2017; 123: $120-133$.

3. Baldoni NR, Aquino JA, Alves GCS, Sartorelli DS, Franco LJ, Madeira SP, et al. Prevalence of overweight and obesity in the adult indigenous population in Brazil: a systematic review with meta-analysis. Diabetes Metab Syndr 2019; 13: 17051715.

4. Prince SA, MCDonnell LA, Turek MA, Visintini S, Nahwegahbow A, Kandasamy $S$, et al. The state of affairs for cardiovascular health research in Indigenous women in Canada: a scoping review. Can J Cardiol 2018; 34: 437-449.

5. Department of Statistics Malaysia. Population distribution and basic demographic characteristics 2010. Kuala Lumpur: Population and Housing Census of Malaysia, 2010.

6. Department of Orang Asli Development. Pelan Strategik Jabatan Kemajuan Orang Asli: 2016-2020. JAKOA: Kuala Lumpur, 2016.

7. Wong YS, Allotey $P$, Reidpath DD. Sustainable development goals, universal health coverage and equity in health systems: the Orang Asli commons approach.Glob Health Epidemiol Genom. 2016;1: e12.

8. Hussain TP, Krishnasamy DS, Hassan AA. Resettlement of the Orang Asli and development plan for Orang Asli community in Malaysia. Journal of Techno Social. 2017;9(1): 32-43. 
9. Institute for Public Health. National health and morbidity survey 2015 vol III: healthcare demand. Kuala Lumpur: Ministry of Health Malaysia, 2015.

10. Endicott K. Malaysia's original people: past, present and future of the Orang Asli. Singapore: NUS Press, 2015.

11. Rosnon MR, Gill SS, Badari SAZ, Ab Rahman NAFW, Goh ADH. Petunjuk pembangunan komuniti orang Asli: Suatu analisis penggunaan barangan dan perkhidmatan. Geografia Malays J Soc Space 2019; 15: 132-146.

12. Yew VW. Collecting qualitative research data on health seeking behaviour of Peninsular Malaysia's aboriginal people. Geografia-Malaysian Journal of Society and Space. 2017; 11(11): 45 - 52.

13. Bartholomew CV, Abdullah MT, Abdullah R, Clements GR. Etho-Tourism: A Review on Natural Resources Use Pattern by Indigenous Community in Peninsular Malaysia. 2nd International Conference on Adventure and Ecotourism 2015; 4-8 December 2015; Adya Hotel, Langkawi Island: Faculty of Forestry, Universiti Putra Malaysia; 2017. p. 84-95.

14. Phipps ME, Chan KK, Naidu R, Mohamad NW, Hoh BP, Quek KF, Ahmad B, Harnida SM, Zain AZ, Kadir KA. Cardio-metabolic health risks in indigenous populations of Southeast Asia and the influence of urbanization. BMC Public Health. 2015 Dec;15(1):1-8.

15. Ithnin M, Juliana N, Mohamad Nor NAU, Effendy NM, Rani MDM. Knowledge, attitude, and practices of noncommunicable diseases: comparison between Orang Asli and Malay from rural area in Negeri Sembilan, Malaysia: a comparative study. Malaysian J Public Health Med 2020; 20: 131-140.

16. Wong YS, Allotey P, Reidpath DD. Why we run when the doctor comes: Orang Asli responses to health systems in transition in Malaysia. Crit Public Health 2019; 29: 192-204.

17. Poortaghi S, Raiesifar A, Bozorgzad P, Golzari SE, Parvizy S, Rafii F. Evolutionary concept analysis of health seeking behavior in nursing: a systematic review. BMC health services research. 2015;15 (1):1-8.

18. Mackian S. A review of health seeking behaviour: problems and prospects. United Kingdom: Health Systems
Development Programme. University of Manchester, England 2003.

19. Shorten A, Smith J. Mixed methods research: expanding the evidence base. Evidence Based Nurs 2017;20 (3):74-5.

20. Sharma SK, Mudgal SK, Thakur K, Gaur R. How to calculate sample size for observational and experimental nursing research studies?. Natl J Physiol Pharm Pharmacol. 2020;10 (1): 1-8.

21. Ashari LS, Mitra AK, Rahman TA, Mitra A, Teh LK, Salleh MZ, et al. Prevalence and risk factors of metabolic syndrome among an endangered tribal population in Malaysia using harmonized IDF criteria. Int J Diabetes Dev Countries 2016; 36: 352358.

22. Aziz TA, Teh LK, Md Idris MH, Bannur Z, Ashari LS, Ismail Al, et al. Increased risks of cardiovascular diseases and insulin resistance among the Orang Asli in Peninsular Malaysia. BMC Public Health 2016; 16: 284.

23. Saunders B, Sim J, Kingstone T, Baker S, Waterfield J, Bartlam B, et al. Saturation in qualitative research: exploring its conceptualization and operationalization. Qual Quant 2018; 52: 1893-1907.

24. Moser A, Korstjens I. Series: Practical guidance to qualitative research. Part 3: Sampling, data collection and analysis. European Journal of General Practice. 2018; 24 (1):9-18.

25. Creswell JW, Hirose M. Mixed methods and survey research in family medicine and community health. Fam Med Community Health 2019; 7(2): e000086.[AQ: 8]

26. Abdullah J, Borhan MA-A, Ahmad CB. Orang Asli resettlement in urban environment at Bukit Lanjan, Selangor, Malaysia. Procedia Soc Behav Sci 2015; 201:71-79.

27. Masron T, Masami F, Ismail N. Orang Asli in Peninsular Malaysia: population, spatial distribution and socio-economic condition. J Ritsumeikan Soc Sci Human 2013; 6: 75-115.

28. Ministry of Education, Malaysia. Malaysian education blueprint 2013-2025. Putrajaya, Malaysia: Ministry of Education, 2013, https: / /www.moe.gov.my/images/dasar$\mathrm{kpm} /$ articlefile_file_003108.pdf 
29. Yusoff RM, Halim SA, Pereira JJ. Impak Rancangan Pengumpulan Semula (RPS) ke atas Komuniti Orang Asli Jahai di Rancangan Pengumpulan Semula Air Banun, Perak. [The Impact of Resettlement Programme on the Jahai Community in Rancangan Pengumpulan Semula Air Banun, Perak]. Asian J Environ Hist Heritage 2019; 3: 175-182.

30. Lendik LS, Chan MY, Renganathan S, Yap NT. Metaphor and the representations of health and illness among the Semai indigenous community in Malaysia. GEMA Online ${ }^{\circledR}$ Journal of Language Studies. 2017;17(4): 61-83.

31. Alias A, Salleh H, Mohamad Ismail S, Aziz Abdul Ghani Aziz S, Salleh MS, Kamri KA, Noor Saarani A, Druis MD. Traditional knowledge management and usage of medicinal plants as daily medication in healing rituals among the Batek of Kuala Koh, Gua Musang, Kelantan: an exploratory evidence. International Journal of Engineering \& Technology. 2018;7 (2.29):980-9.

32. Adeeb MN, Kumarasamy K, Hamid SA, Mahat NA, Arumugam K, Shukor SH. Knowledge and Attitude of Neonatal Jaundice-Orang Asli Perspective. Jurnal Sains Kesihatan Malaysia (Malaysian Journal of Health Sciences). 2016;14(2). 65-68

33. World Health Organization Regional Office for South-East Asia. Action plan for the prevention and control of noncommunicable diseases in South-East Asia, 2013-2020. 2013. New Delhi, India: World Health Organization. https: / / www.iccp- portal.org/sites/default/files/resources/ sea-ncd-89\%28reduced\%29.pdf

34. Bennett PN, Wang W, Moore M, et al. Care partner: a concept analysis. Nurs Outlook 2017; 65: 184-194.

35. Helgeson VS, Jakubiak B, Van Vleet $M$, Zajdel $M$. Communal coping and adjustment to chronic illness: theory update and evidence. Pers Soc Psychol Rev 2017; 22: 170-195.

36. Aniza I, Norhayati M, Norfazilah A. Development and validation of a questionnaire on socio-cultural factors among the Orang Asli and general population in Selangor. Malaysian J Public Health Med 2017; 17: 140-150.

37. Chin YW. Impact of Doctor-Patient Communication in Health Status of the Indigenous People in Peninsular Malaysia. e-Bangi. 2021;18 (2): 29-39.

38. Ramli MR, Malek S, Milow P, Aziz NJ. Traditional knowledge of medicinal plants in the Kampung Orang Asli Donglai Baru, Hulu Langat, Malaysia. Biodiversitas Journal of Biological Diversity. 2021 Feb 20; 22(3):1304-1309.

39. Sills J. Protect indigenous peoples from COVID-19. Science 2020; 368: 251-251.

40. Berger ZD, Evans NG, Phelan AL, Silverman RD. Covid-19: control measures must be equitable and inclusive. BMJ 2020; 368: m1141. 